\title{
Reduction of Health Care Costs by Utilization of High Quality Medical Care
}

\section{F. Crowder}

Qualitätsmanagement

Keywords

cost control

high quality medical care

pay for performance

complications

Schlüsselwörter

Kostenkontrolle

Ergebnisqualität

- Ergebnisorientierte

Vergütung

Komplikationen
Institut

Western Division Medical Director, Alpha Natural Resources,

Powder River Coal

Bibliografie

DOI 10.1055/s-0029-1242679

Dtsch Med Wochenschr 2009;

134: S324 - (c) Georg Thieme

Verlag KG Stuttgart - New York . ISSN 0012-0472

\section{Korrespondenz}

David F. Crowder, M. D.

Western Division Medical Director, Alpha Natural Resources,

Powder River Coal

4067 Valley Oak Drive

Loveland, CO 80538

eMail dcrowder@alphanr.com
In 2001 the cost of health benefits was escalating at a non-sustainable rate for Powder River Coal and Alpha Natural Resources. Coal prices had fallen to a point where profit was marginal. A program of cost reduction was needed quickly to be able to continue current benefits. The alternative was reduction in benefits, a move to which the companies were averse.

Many of the usual mechanisms for cost control were attempted. Meetings were held with hospitals and providers seeking preferential consideration and discounts. The response from the provider community was negative. The companies were concerned by the re-operation rates for certain expensive surgical procedures. The length of hospitalization in the local area was above average. Anecdotal information suggested excessive complications were being experienced following complex surgery performed in the area. Despite the mines having the highest quality of medical insurance in the region access to care was often difficult. The employee population as well as management was dissatisfied with local care. Providers were out of touch with their costs and their outcomes.

At this time the Leapfrog Group was coming into existence touting quality of care as a cost reducer. This concept seemed rational. It was an approach the companies could take with no participation by other parties. The major hurdle for the companies in rural Wyoming was the distance to major centers for care. In order to facilitate the use of these „Centers of Excellence“ (COE), incentives including reduction in co-pay and reimbursement for travel expenses were offered to employees. The COE providers had to be in the upper $7 \%$ of objectively measured outcomes for their designated services. Other parameters included patient safety, patient satisfaction, location and cost over time.

A pilot project was instituted including only orthopedics and spinal surgery, two areas where cost and outcomes were a problem. To the companies' surprise, even with incentives the cost for care was often equal to or less than local providers. The absence of re-operation and complications became quickly apparent. Furthermore employees and their families were experiencing greater patient satisfaction from the COE care. More time was being taken with patients. Patients sensed they were of greater importance to the COE providers than those locally. At first obtaining feedback from the companies' third party administrators on cost was difficult and delayed any real analysis. The one certain observation was that costs seemed to be in control and subjectively the complication rate and re-operation rate seemed less. At no time was any attempt made to secure special discounts or other financial considerations from COE providers. That policy still continues.

Based on experience the COE Program was expanded to include a broad spectrum of services. Data was improving and beginning to show definite cost control. A review of statistics for Alpha Natural Resources for the years 2005 through 2008 showed a true $5 \%$ per year decrease in costs. The average cost increase during that period for the United States was 7,7 \% per year. The cost control allowed Alpha to add 92 employees with no additional total health benefits cost. The most significant parameter to explain the reduction in cost was a $10 \%$ per year decrease in the number of hospital days. This observation makes sense in the light of the high cost of any service performed in an institutional setting.

Cost of the COE program has been reasonable. The author has been paid an average of $\$ 60,000$ US per year to maintain the program and act as an ombudsman for the employees and their families. Costs for data have only been about $\$ 100$ US per year. With an annualized savings of $\$ 1,740,763.75$ US counting a $7 \%$ per year cost escalation the return on investment (ROI) is 28.44. Looking at only savings and not adding inflation the ROI is still 13.13 . Employee monthly premiums remain in the range of $\$ 70$ to $\$ 120$ for health benefits.

The Centers of Excellence Program continues to be expanded and reviewed biennially. In addition, new programs now include prevention, life style alteration, disease control and primary care administered through a comprehensive family health center owned by the companies.

Author's declaration: The author does not have any financial interests or conflicts of interest relevant to the subject of this manuskript. 